ORIGINAL ARTICLE

\title{
Can interfaith research partnerships develop new paradigms for condom use and HIV prevention? The implementation of conceptual events in Malawi results in a 'spiritualised condom'
}

\author{
Dennis G Willms, ${ }^{1}$ Maria-Ines Arratia, ${ }^{2}$ Patrick Makondesa ${ }^{3}$
}

\begin{abstract}
- Additional materials are published online only. To view these files please visit the journal online (http://sti.bmj. com).

${ }^{1}$ Salama SHIELD Foundation, Plattsville, Ontario, Canada ${ }^{2}$ Department of Anthropology, McMaster University, Hamilton, Ontario, Canada

${ }^{3}$ International Labour

Organization, Lilongwe, Malawi
\end{abstract}

Correspondence to Dr Dennis G Willms, Salama SHIELD Foundation, PO Box 407, Plattsville, ON NOJ 1SO,

Canada; info@salamashield.org

Accepted 11 September 2011 Published Online First 8 October 2011

\section{(2) UNLOCK:D}

This paper is freely available online under the BMJ Journals unlocked scheme, see http://sti. bmj.com/site/about/unlocked. xhtml

\section{ABSTRACT}

Objectives The aim of this intervention research study was to engage senior leaders of faith-based organisations (FBOs) in Malawi in a participatory process to construct an interfaith theology of HIV/AIDS. This process was designed to enhance the capacity of faith leaders to respond more effectively to the HIV/AIDS pandemic.

Methods An evidence-driven combination of ethnographic and participatory action research methodologies was utilised. Conceptual events-innovative participatory action research processes - were held over the 4-year project and brought together health service providers, policy makers and a non-governmental organisation in partnership with FBOs and grassroots faith-based communities.

Results Through facilitated dialogue, an interfaith theology of HIV/AIDS emerged, resulting in the proposition that a 'spiritualised condom' endorses a 'theology of protecting life'. This proposition was based on the following convictions: (1) life is sacred and to be protected, (2) to kill or murder is a 'greater sin' than the 'lesser sin of infidelity', (3) protection of the innocent is a moral and religious requirement, (4) condoms have the potential to prevent the death of an innocent person and (5) condoms need to be encouraged, even in the context of marriage.

Conclusions Clinicians, non-governmental organisations, health service providers and policy makers, assisted by health social scientists, can successfully partner with FBOs and their leaders to (1) modify and transform faith-based understandings of HIV risk and (2) bring about attitudinal and behaviour changes that help to address the challenges associated with HIV/AIDS.

\section{INTRODUCTION}

The Republic of Malawi is a country in southcentral Africa, with a population of 12 million and around 200000 HIV-infected people in need of antiretroviral therapy, ${ }^{1}$ and almost 90000 new HIV infections per year. ${ }^{2}$ The national adult HIV prevalence rate is $12 \%,{ }^{2}$ one of the highest in the world, and the number of individuals aged $0-49$ years living with HIV/AIDS is between 0.7 and 1.1 million. ${ }^{3}$ More than half a million children in Malawi have been orphaned by AIDS. ${ }^{4}$

Most HIV-infected Malawians are unaware of their HIV infection and do not use condoms. ${ }^{5}$ Many Malawians are not convinced that condoms are safe or capable of preventing HIV transmission, and many distrust condom marketing campaigns, believing them to be population control efforts by the Malawian government and the international community. ${ }^{6}{ }^{7}$ While there is some discussion among Malawians of condom use in the context of extramarital relationships, condom use within marriage relationships is very limited. ${ }^{8}$

It is widely acknowledged that there is potential for faith-based organisations (FBOs) to play an important role in HIV/AIDS prevention. ${ }^{9-15}$ However, FBOs can be hampered in this role by sociocultural and theological factors. ${ }^{14}{ }^{16-18}$ In many cultural settings, including Malawi, faith leaders actively discourage condom use. ${ }^{17-19}$

Malawi's FBOs are well positioned to fight the HIV/AIDS epidemic, ${ }^{20}$ but their effectiveness is limited by cultural and theological factors that inhibit dialogue on the disease and its prevention. ${ }^{18}$ Faith persuasions in Malawi have traditionally been isolated from each other. In addition, many faith leaders continue to promote a theology replete with sin, blame and immorality, which contributes to experiences of stigma and discrimination. These faith leaders have generally discouraged condom use because they believe that it inadvertently encourages infidelity and adultery and creates an unnatural reproductive barrier..$^{18}$ In Malawi, where procreation is linked in African Traditional Religions to fertility, sexuality, bodily fluids and the land, any reproductive barrier is thought to be disruptive and inconsistent with the demands of the ancestors. ${ }^{18} 21$

\section{OBJECTIVES}

Changing the ways in which Malawians address the problem of HIV/AIDS requires that the senior leaders of FBOs in Malawi be engaged as enabling resources to promote attitudinal and behavioural change. The aim of our research was to construct an interfaith theology of HIV/AIDS that would enhance the capacity of these faith leaders to respond effectively to the HIV/AIDS epidemic.

Our findings in year one of this project revealed that while faith leaders in Malawi were committed to constructive dialogue about HIV/AIDS, they had profoundly different perspectives on the issue, and these differences were contributing to their inability to communicate and work together to promote the attitudinal and behavioural changes necessary to stop the spread of HIV. ${ }^{18}$ They required a new, practical, interfaith theological argument to guide their response to the epidemic. 
Because the beliefs of faith-based groups in Malawi do not easily integrate scientific perspectives, innovative processes were required to ensure that this new theology would be infused with the latest scientific knowledge about HIV/AIDS. ${ }^{21}$

Using the conceptual event (CE), an innovative participatory action research (PAR) process, ${ }^{18}$ our 4 -year project (beginning in 2002) set out to determine whether health service providers, health policy makers and a non-governmental organisation could partner with $\mathrm{FBOs}$ and grassroots faith-based communities (FBCs) in Malawi to construct a theology of HIV/AIDs. The goal was to construct a theology that modifies faith-based understandings of HIV/AIDS risk, facilitates dialogue and behaviour change, de-stigmatises the disease and encourages condom use as a method of preventing the spread of HIV. While transformed, ecumenical theologies do not automatically lead to behaviour change, they can facilitate behaviour change when they are practical; in turn, the development of more compassionate behaviours can lead to revised theological thinking. ${ }^{22}$

\section{METHODS}

At the core of this project's achievements were the unique, collaborative research partnerships developed among health service providers and scientists, 24 Christian and Muslim FBOs (see online appendix 1), FBCs, the Department of Theology and Religious Studies and College of Medicine at the University of Malawi, the National AIDS Commission of the Republic of Malawi and the Salama SHIELD Foundation (SSF). SSF is an international non-governmental organisation promoting partnerships in developing countries; it draws on indigenous wisdom, scientific knowledge and spiritual values to construct sustainable solutions in response to development concerns (http://www.salamashield.org).

We utilised an evidence-driven combination of ethnographic and PAR methodologies, described in a report on our preliminary findings (year one) $)^{18}$ and in other publications ${ }^{23-30}$ (see box 1). CEs were the principal method used to meet the objectives of this project. A CE, an innovative iteration of the PAR process, is a facilitated, creative problem-based forum that intentionally nudges individuals with different perspectives towards the

Box 1 Participatory action research (PAR) and conceptual events (CEs)

PAR involves cycles of dialogue, reflection and practice that bring people to a critical consciousness of their situation; from this consciousness, they generate new knowledge and social action aimed to transform their circumstances. PAR engages significant leaders (key communicators) and stakeholders in a process of (a) consensually identifying the problem; (b) analysing the problem contextually and culturally; (c) representing the problem in quantitative and qualitative terms; (d) proposing responses to the problem; (e) implementing the responses conceptually and behaviourally and (f) evaluating the impact of the proposed response or solution to the problem. We used CEs to advance this research.

The $C E$, an innovative PAR process, is a facilitated, creative problem-based forum that intentionally nudges individuals with different perspectives towards the construction of a shared ethically compelling framework for understanding a problem and devising solutions (see online appendix 2). construction of a shared ethically compelling framework for understanding a problem and devising solutions ${ }^{18}$ (see online appendix 2).

As the implementing partner in this project, Salama SHIELD Foundation-Malawi (SSF-M) introduced the CE to Malawi's FBOs and FBCs as a PAR process, ${ }^{30}$ deliberately designed to bring together faith leaders who are affected by HIV/AIDS and who share the goal of finding life-sustaining solutions to the problems caused by this disease, but who nonetheless have profoundly different understandings of the fundamental truths governing their lives, the determinants of health and illness in the context of HIV/AIDS and how they should respond to evidence of risk.

Three Lilongwe-area CEs were held in 2004 to bring these faith leaders together to engage in critical reflective dialogue on the contentious issues that divide them in the areas of HIV/ AIDS prevention, supportive care and education and on what they should say and do about the epidemic. At the first CE, the Nantipwiri Colloquium, papers were presented by faith leaders ${ }^{31}$ who contributed valuable theological expertise to the dialogue. Physicians provided clinical and scientific information on the characteristics of HIV transmission and the safety of condom use. Other participants presented grassroots views on HIV/AIDS (gathered in meetings of FBCs and other community groups) through the use of oral reports, drama, dance, songs and poetry, encouraging the faith leaders to rethink their theologies in terms of practical problems on the ground (see online appendix 3 for a list of participants and their contributions). In two follow-up CEs at the Ryalls Hotel and Superior Hotel in Blantyre, cofacilitated by the first author (medical anthropologist) and heads of FBOs, senior leaders of the mainline churches met for further discussion and decision making. These deliberations led to three key CEs in 2005 and 2006 and many other CEs throughout the period of the project, including meetings within faith groups and monthly interfaith meetings with Lilongwe faith leaders. Decisions were made on the basis of consensus-after strenuous discussion. Our methodologies for analysis and interpretation of these CEs have been previously described in a report on this project's preliminary findings in year $1^{18}$ (see online appendix 4).

\section{RESULTS}

The CEs organised by this project were historic events for Malawi's FBOs and FBCs and their leadership. While these faith leaders live and work in close proximity to each other in Blantyre, Lilongwe and Zomba, most had not worked together or even interacted in any meaningful way for many years (James Tengatenga, Co-Chair, Nantipwiri Colloquium, personal communication, 24 July 2004). Yet remarkably, all the leaders of the umbrella bodies of faith communities, the mainline churches and the independent and smaller churches of Malawi came to be highly committed to this project and its objectives. All actively participated in our Lilongwe-area interventions and some pastors were trained as field workers and assisted with research throughout the project period.

The CEs challenged these faith leaders to examine their theological stances, bridge diverse perspectives, construct shared solutions, change the ways in which they discussed HIV/AIDS issues with their communities and modify their approaches to HIV/AIDS prevention, supportive care and education.

There were surprising changes during this process in the ways in which Malawi's faith leaders approached faith and its relationship to HIV/AIDS. Over the course of the many CEs that took place in 4 years (see online appendix 5), a new theology of HIV/AIDS began to emerge. On 28 September 2004, all heads of 
the mainline Christian churches and Muslim FBOs in Malawi signed a statement that they named The Ryalls Declaration (online appendix 6), committing themselves to ongoing dialogue on contentious issues surrounding HIV/AIDS, the continued development of an interfaith theology of HIV/AIDS, the support of programmes and practices that contribute to the prevention of HIV/AIDS and to the reduction of the stigma and discrimination associated with it. To help implement the declaration's pioneering objectives, these faith leaders established a Forum for theological dialogue and research on HIV/AIDS. At a meeting of this Forum in January 2006, the participating faith leaders issued a landmark statement to the press, promoting the use of condoms to protect innocent life (see box 2).

Over time, the dialogue at the CEs shifted and changed as the $\mathrm{FBO}$ and $\mathrm{FBC}$ leaders exchanged ideas and theological arguments on the subjects of HIV/AIDS prevention and condom use. Eventually, these leaders developed an effective way to graft prevention messages onto a moral imperative and committed themselves to implementing within their communities a systematic and practical theology of protecting life, based on the following convictions.

1. Life is sacred and to be protected.

2. To kill or murder is a 'greater sin' than the 'lesser sin' of infidelity.

3. Protection of the innocent is a moral and religious requirement.

4. Condoms have the potential to prevent the death of an innocent person (the unsuspecting spouse or partner of a person with multiple sexual partners).

5. Therefore, condom use needs to be encouraged, even in the context of marriage.

While Pope Benedict XVI's recent comments ${ }^{32}$ acknowledged that the use of condoms to prevent the spread of HIV is a lesser evil than putting the life of another human being at risk (and this is significant for his followers around the world), the Vatican still holds that condom use is immoral, ${ }^{33}$ even in the context of a marriage in which the condom has the 'double effect' of preventing HIV transmission in addition to pregnancy.

In contrast, the diverse group of Malawian faith leaders involved in this research project came to the surprising conclusion that under the circumstances in which their faith communities find themselves, a theology of protecting life, based on scripture, makes condom use a moral and religious imperative.

Box 2 Forum for theological dialogue and research on HIV/ AIDS, Press Release Excerpt Victoria Hotel, Blantyre, Malawi 27 January 2006

[We] do realize that in certain circumstances, if properly used, [the condom] does contribute to the saving of innocent life. [We] emphasize the responsibility of the unfaithful to at least reduce the effects of their actions on their unsuspecting partners by the use of condoms. The same God who says, "Do not commit adultery" equally says, "Do not kill."

In view of the serious effects of the pandemic on our communities, we emphasise the need for increased integration of counselling in our pastoral work and in the training of religious leaders. In order to protect life, we emphasise the need for a dramatic increase in voluntary counselling and testing. We also see that declaring one's status may help to save life and decrease stigma.
They concluded that this theology, emerging from their reflections in the CEs, had yielded a new concept they called 'the spiritualised condom ${ }^{34}$ (see online appendix 7).

The spiritualised condom refers to a profound linkage between the technology of HIV prevention and a shared moral purpose-to protect life. Among individuals whose behavioural choices are driven by ancestral authorities and whose epistemological references are more spiritual and indigenous than secular or biomedical, the spiritualised condom legitimises public health strategies for HIV prevention. With the concept of the spiritualised condom, the public health requirement of condom use is given spiritual authority, which in this instance transcends a variety of faith traditions.

The development of the idea of the spiritualised condom reflected the realisation among these faith leaders that condom use is an ethical act, required by their own moral beliefs and by a theology that sanctifies life. The spiritualised condom endorses prevention in a novel and positive way.

One of the Malawian co-facilitators of the CEs put it this way:

Can the faith community in Malawi justify its moral stance on condoms in the face of this pandemic? I am persuaded to say that it cannot. There is a good at stake, and that good for me is life. The question then is shall we save life or let it die? ... The choice is on the side of life.

\section{DISCUSSION}

This project demonstrated that the participatory process of CEs can translate the intellectual and experiential capacity of multiple stakeholders, including faith leaders, into effective strategies and solutions for HIV prevention.

This research focused on faith leaders, challenging them to radically transform their theologies and communicative behaviours in ways that could potentially lead to behaviour change among their followers and encourage condom use. Though many questions remain for future research (online appendix 8), we observed significant changes over the course of our CEs in the ways in which faith leaders communicated with each other and their followers about HIV/AIDS.

While unique and innovative research partnerships were created between health scientists, health service providers and diverse FBOs and FBCs, our methodology has a number of limitations with regard to its ability to achieve intervention effectiveness for individuals at risk for HIV/AIDS. The effectiveness of these partnerships was hampered to some degree by the cultural and epistemological divide that existed between researchers with scientific and faith-based backgrounds and by the ongoing challenge of involving more Malawians in this research. While our research partners were representative of the mainline FBOs in Malawi, they did not include, for example, the leaders of the African Traditional Religion sector in Malawian society-though some traditional views were reflected in the information gathered from meetings of FBCs. Furthermore, qualitative studies, such as this one, are complex and costly and can require a long time period before hoped-for results can be demonstrated at the clinical level. Follow-up studies are in the works and will incorporate qualitative and quantitative methodologies to measure the impact and behaviour outcomes of this intervention within Malawi's FBOs. Although the merit of our CE process in other African settings is uncertain, its application in settings outside Malawi could test its generalisability and potentially lead to the development of practices that could be utilised effectively by other faith communities in the region. 


\section{Key messages}

- Conceptual events -innovative participatory processes - can translate the intellectual and experiential capacity of multiple stakeholders into effective strategies for HIV prevention.

- Healthcare stakeholders (clinicians, policy makers, researchers), in partnership with faith-based organisations, can bring about attitudinal and behavioural changes with respect to HIV risk.

- The implementation of conceptual events has produced an interfaith consensus on condom use as a moral imperative despite initial resistance and disagreement.

- Interfaith research partnerships have led to the concept of a 'spiritualised condom', which legitimises public health strategies for HIV prevention among Malawi's indigenous communities.

By entering respectfully into the cultural and epistemological divides that exist between researchers, governments and faith communities, we believe that research partnerships such as those described here can modify faith-based understandings of HIV/AIDS and build on common ground, leading to long-term health solutions.

Acknowledgements We thank the Department of Theology and Religious Studies, Chancellor College, University of Malawi for partnering with the Salama SHIELD Foundation-Malawi (SSF-M) to organise CEs. The authors are indebted to: Dr Dixie Maluwa Banda, Professor of Education and Psychology, University of Malawi, for his expertise in the area of behaviour change; Dr John Kumwenda, Department of Medicine, College of Medicine, University of Malawi, for his expertise in the areas of HIV/AIDS treatment and management; and Dr Nelson Sewankambo, Professor of Medicine and Principal at the College of Health Sciences, Makerere University, Uganda, for his expert contributions to this project's CEs. Special appreciation goes to the leaders of FBOs who attended all of the CEs and who established the Forum for theological dialogue and research on HIVIAIDS; among them were the following (in alphabetical order): Reverend (Rev) Mezuwa Banda, Father Dr Joseph C Chakanza, Right Rev Dr Felix Chingota, Rev Dr Macford Chipuliko, Dr Klaus Fiedler, Rev Fletcher Kaiya, Right Rev Bishop Patrick Kalilombe, Sheik Dr Imran Shereef Mahomed, Archbishop Bernard Malango, Rev Dr Geoffrey Matoga, Dr Sostain Mfune, Bishop Musikuwa, Pastor Canaan Phiri, Sheik Sanudi, Monsignor Montfort Sitima and Right Rev Bishop James Tengatenga. Sincere thanks to Professor Deborah Cook, Department of Clinical Epidemiology and Biostatistics, McMaster University, Hamilton, ON, Canada, for her support and constructive comments on the paper. We also recognise and are grateful for the excellent editorial direction and assistance of Ms Jane Willms. Finally, we thank the editors for their constructive, helpful,and supportive comments.

Funding Canadian Institute of Health Research (ClHR) grant (No. HHP-53379), National AIDS Commission (NAC) grants (Ref. No. NAC/10/05/59 and

NAC/FMA/C/0005) and the Salama SHIELD Foundation (SSF). DGW was supported by McMaster University as a faculty member and a Career Scientist Award from the Ontario HIV Treatment Network (OHTN - ROGC101), M-IA was supported by a CIHR grant (No. HHP-53379), and PM was supported by a CIHR grant (No. 53379).

Competing interests All authors have completed the Unified Competing Interest form (available on request from the corresponding author) and declare that (1) this work was supported by a Canadian Institute of Health Research (CIHR) grant (No. HHP-53379), National AIDS Commission (NAC) grants (Ref. No. NAC/10/05/59 and NAC/FMA/C/0005) and the Salama SHIELD Foundation (which is a not-for-profit organisation, registered in Canada, Malawi and Uganda, that secures its funding primarily through individuals and corporate donors), that DGW was supported by McMaster University as a faculty member and a Career Scientist Award from the Ontario HIV Treatment Network (OHTN-ROGC101), M-IA was supported by a CIHR grant (No. HHP-53379), and PM was supported by a CIHR grant (No. 53379) for the submitted work; (2) the authors have no relationships with companies that might have an interest in the submitted work in the previous 3 years; (3) their spouses, partners or children have no financial relationships that may be relevant to the submitted work and (4) the authors have no non-financial interests that may be relevant to the submitted work. The researchers worked independently from the funders and fulfilled all of the grant requirements for reporting to the CIHR and the NAC. SSF Malawi functioned as the implementing non-governmental organisation (NGO) partner in the research; because it is respected in Malawi, it had easier access to stakeholders and key communicators among faith-based organisations (FBOs) and faith-based communities than an academic team from McMaster University with no direct affiliation to either the University of Malawi or the FBO administrative bodies would have had.

Ethical approval Ethical approval provided by the McMaster University Research Ethics Board (REB File No. 2002 023), which ensured compliance with the Tri-Counci Policy Statement and the McMaster University Policies and Guidelines for Research Involving Human Participants. Participants gave informed consent before taking part.

Contributors This research was conceived and designed by DGW, who wrote the grant proposal to the Canadian Institute of Health Research, hired PM and M-IA and co-facilitated all the conceptual events. PM oversaw data gathering and, with research assistants (RAs), conducted interviews and focus groups. M-IA managed the project, conducted interfaith and intercultural workshops and co-wrote with DGW the grant proposal to the National AIDS Commission. DGW, PM, M-IA and RAs participated in the analysis and interpretation of data. All three authors co-wrote reports to the donors, participated in drafting or critically revising this article and gave final approval of the version to be published. All authors had full access to all of the data in the study and can take responsibility for the integrity of the data and the accuracy of the data analysis. Jane Willms provided editorial direction and helped to draft and revise this article. DGW is guarantor.

Provenance and peer review Not commissioned; externally peer reviewed.

Data sharing statement Transcripts of the conceptual events are available upon request to researchers for review, interpretation and analysis.

\section{REFERENCES}

1. National AIDS Commission Malawi. HIV and Syphilis Sero-Survey and National HIV Prevalence Estimates Report 2005. Lilongwe, Malawi: Ministry of Health, Republic of Malawi, 2005. http://www.medcol.mw/commhealth/publications/HIV\% 20sentinel\%20surveillance\%202005.doc.

2. National AIDS Commission Malawi. National HIV Prevention Strategy 2009-2013. Lilongwe, Malawi: Republic of Malawi, 2009. http://www.aidsmalawi. org.mw/index.php?option $=$ com_rokdownloads\&view $=$ filegtask $=$ downloadgid $=19 \%$ 3Anational-hiv-prevention-strategy $\mathbf{y}$ Itemid $=60$.

3. WHO. Malawi. Summary Country Profile for HIVIAIDS Treatment Scale-up. 2005 http://www.who.int/hiv/HIVCP MWI.pdf

4. Malawi Department of Nutrition, HIV and AIDS. Malawi HIV and AIDS Monitoring and Evaluation Report, 2007: follow up to the United Nations Declaration of Commitment on HIV and AIDS. Lilongwe, Malawi: Republic of Malawi, 2007. http://www.docstoc.com/docs/2922629/REPUBLIC-OF-MALAWI-MALAWI-HIV-ANDAIDS-MONITORING-AND-EVALUATION

5. Anand A, Shiraishi RW, Bunnell RE, et al. Knowledge of HIV status, sexual risk behaviors and contraceptive need among people living with HIV in Kenya and Malawi. AIDS 2009;23:1565-73. http://www.ncbi.nlm.nih.gov/pubmed/19542867.

6. Kaler A. The moral lens of population control: condoms and controversies in southern Malawi. Stud Fam Plann 2004;35:105-15. http://www.ncbi.nlm.nih.gov/ pubmed/15260212.

7. Muula AS. Condom and sexual abstinence talk in the Malawi National Assembly. Afr Health Sci 2006;6:21-6. http://www.ncbi.nlm.nih.gov/pmc/articles/PMC1831960/.

8. Chimbiri AM. The condom is an 'intruder' in marriage: evidence from rural Malawi. Soc Sci Med 2007;64:1102-15. http://linkinghub.elsevier.com/retrieve/pii/ S0277953606005120.

9. Green EC. Faith-Based Organizations: Contributions to HIV Prevention. Washington, DC: The Synergy Project, USAID, 2003. http://www.docstoc.com/docs/677395/ Faith-Based-Organizations-Contributions-to-HIV-Prevention--USAID-Health-HIVAIDS Partnerships-Faith-Based-Organizations, http://www.usaid.gov/our work/ global_health/aids/TechAreas/community/fbo.pdf.

10. Byamugisha G, Steinitz LY, Williams G, et al. Journeys of Faith: Church-Based Responses to HIV and AIDS in Three Southern African Countries. St. Albans, Herts, UK: TALC, 2002. http://www.sarpn.org.za/documents/d0001614/FBO-HIV_SouthernAfrica June2002.pdf.

11. Agadjanian V. Gender, religious involvement, and HIV/AIDS prevention in Mozambique. Soc Sci Med 2005;61:1529-39. http://www.ncbi.nlm.nih.gov/pubmed/15869833.

12. Trinitapoli J. Religious teachings and influences on the ABCs of HIV prevention in Malawi. Soc Sci Med 2009;69:199-209. http://www.ncbi.nlm.nih.gov/pubmed/ 19447536.

13. POLICY Project. POLICY Fact Sheet: Strengthening Faith-Based Responses to HIV/ AIDS. Washington, DC: Futures Group, 2004. http://www.policyproject.com/pubs/ brochures/POLICY FBO and HIV Factsheet.pdf.

14. Muturi N. Faith-based initiatives in response to HIV/AIDS in Jamaica. Int J Comm 2008;2:108-31. http://ijoc.org/ojs/index.php/ijoc/article/viewFile/167/123.

15. McCreary LL, Kaponda CP, Norr KF, et al. Rural Malawians' perceptions of HIV risk behaviors and their sociocultural context. AIDS Care 2008;20:946-57. http://www. ncbi.nlm.nih.gov/pubmed/18608060

16. Agadjanian V, Sen S. Promises and challenges of faith-based AIDS care and support in Mozambique. Am J Public Health 2007;97:362-6. http://www.ncbi.nlm. nih.gov/pmc/articles/PMC1781404/. 
17. Marshall M, Taylor N. Tackling HIV and AIDS with faith-based communities: learning from attitudes on gender relations and sexual rights within local evangelical churches in Burkina Faso, Zimbabwe, and South Africa. Gend Dev 2006;14:363-74. http://www.informaworld.com/smpp/content $\sim$ content $=a 758084554 \sim \mathrm{db}=$ all.

18. Willms DG, Arratia MI, Makondesa P. Malawi faith communities responding to HIV/ AIDS: preliminary findings of a knowledge translation and participatory-action research (PAR) project. Afr J Aids Res 2004;3:23-32. http://ajol.info/index.php/ajar/ article/view/7140.

19. Rankin SH, Lindgren T, Kools SM, et al. The condom divide: disenfranchisement of Malawi women by church and state. J Obstet Gynecol Neonatal Nurs 2008;37:596-606. http://www.ncbi.nlm.nih.gov/pubmed/18811780.

20. National AIDS Control Programme, Ministry of Health and Population, Malawi. Malawi's National Response to HIVIAIDS for 2000-2004: Combating HIV/ AIDS With Renewed Hope and Vigour in the New Millennium. Lilongwe, Malawi: Republic of Malawi, 2000. http://www.youth-policy.com/Policies/ Malawi_Natl_Response to_HIV_AIDS.pdf.

21. Willms DG, Johnson NA, Chingono $A$, et al. AIDS prevention in the matare and the community: a training strategy for traditional healers in Zimbabwe. In: Higginbotham N, Briceño-León R, Johnson N, eds. Applying Health Social Science: Best Practice in the Developing World. Zed Books, 2001:163-82.

22. Byamugisha G. Breaking the Silence on HIVIAIDS in Africa: How can Religious Institutions Talk About Sexual Matters in their Communities? Kampala, Uganda: Tricolour, 2000

23. Willms D. Understanding must precede behavioural change. The Record 2009. http://news.therecord.com/article/513111.

24. Willms DG, Manson-Singer S, Adrien A, et al. Participatory aspects in the qualitative research design of phase II of the Ethnocultural Communities Facing AIDS Study. Can
J Public Health 1996;87(Suppl 1):S15-25. http://www.ncbi.nlm.nih.gov/pubmed/ 8705918 .

25. Willms DG, Best JA, Taylor DW, et al. A systematic approach for using qualitative methods in primary prevention research. Med Anthropol 0 1990:4:391-409. http:// www.jstor.org/pss/649223.

26. Lavis JN, Robertson D, Woodside JM, et al: Knowledge Transfer Study Group. How can research organizations more effectively transfer research knowledge to decision makers. Milbank 0 2003;81:221-48, 171-2. http://www.ncbi.nlm.nih.gov/pubmed/ 12841049 .

27. Suwanwela C, Neufeld V. Health research for development: realities and challenges In: Neufeld V, Johnson N, eds. Forging Links for Health Research: Perspectives from the Council on Health Research for Development. Ottawa: IDRC, 2001.

28. Freire P. Pedagogy of the Oppressed. New York: Seabury, 1970

29. Freire P. Education for Critical Consciousness. New York: Seabury, 1973.

30. Smith SA, Willms DG, Johnson NA, eds. Nurtured by knowledge: learning to do participatory action-research. New York: Apex, 1997; Ottawa: IDRC, 1997

31. Willms DG, ed. Our faiths and HIV: Towards a Theology of Hope and Compassion for the People of Malawi. Zomba, Malawi: Kachere Press, 2010.

32. Pope Benedict XVI. Light of the World: the Pope, the Church, and the Signs of the Times: A Conversation with Peter Seewald. San Franciso: Ignatius Press, 2010.

33. Simpson VL, Winfield N. Vatican: Condom Use Less Evil than Spreading HIV. Associated Press, 2010. http://abcnews.go.com/International/wireStory? id $=12221126$.

34. Willms DG, Makondesa P. Spiritualizing condom use: an interfaith dialogue in Malawi results in a rapprochement with government. AIDS 2006-XVI International AIDS Conference: abstract no. WEPE0825. http://www.aids2006.org./Default.aspx? pageld $=11$ gabstractld $=2199454$ 